\title{
RNA Sequencing Reveals circRNA Expression Profiles in Chicken DF1 Cells Infected with H5N1 Influenza Virus
}

\author{
Li Chen, Guoqin Li, Yong Tian, Tao Zeng, Wenwu Xu, Tiantian Gu and Lizhi Lu*
}

Citation: Chen, L.; Li, G.; Tian, Y.; Zeng, T.; Xu, W.; Gu, T.; Lu, L. RNA Sequencing Reveals circRNA Expression Profiles in Chicken DF1 Cells Infected with H5N1 Influenza Virus. Animals 2022, 12, 158. https://doi.org/10.3390/ ani12020158

Academic Editor: Seiya Yamayoshi

Received: 29 November 2021

Accepted: 3 January 2022

Published: 10 January 2022

Publisher's Note: MDPI stays neutral with regard to jurisdictional claims in published maps and institutional affiliations.

Copyright: (C) 2022 by the authors. Licensee MDPI, Basel, Switzerland. This article is an open access article distributed under the terms and conditions of the Creative Commons Attribution (CC BY) license (https:// creativecommons.org/licenses/by/ $4.0 /)$.
Institute of Animal Husbandry and Veterinary Medicine, Zhejiang Academy of Agricultural Sciences, Hangzhou 310021, China; chenli0429@163.com (L.C.); ligq@zaas.ac.cn (G.L.); tyong@zaas.ac.cn (Y.T.); zengtao4009@126.com (T.Z.); xuwenwu248@outlook.com (W.X.); gtt19931029@126.com (T.G.)

* Correspondence: lulizhibox@163.com; Tel.: +86-0571-8640-4216

Simple Summary: H5N1 is a highly pathogenic avian influenza virus that seriously harms the poultry industry and public health worldwide. However, its pathogenesis is still not well understood In this study, we analyzed the expression profile of circular RNAs (circRNAs) in H5N1-infected chicken embryo fibroblast (DF1) cells and found their expression to change more significantly as the infection was extended. Differentially expressed circRNAs were significantly enriched in terms relating to virus replication and immune response, suggesting that circRNAs play important roles in the pathogenesis of $\mathrm{H} 5 \mathrm{~N} 1$ infection. Our study provides new insights into the mechanisms underlying H5N1-host interaction.

\begin{abstract}
H5N1, a highly pathogenic avian influenza virus that is prevalent in Asia, seriously harms the poultry industry and global public health. However, its pathogenesis is still not well understood. Circular RNAs (circRNAs), a newly identified type of RNA, reportedly play crucial roles in various pathogenic processes. In this study, RNA sequencing was performed to analyze the expression profile of circRNAs in H5N1-infected chicken embryo fibroblast (DF1) cells. A total of 14,586 circRNAs were identified. The expression profiles of infected cells changed more significantly, relative to uninfected cells, as the infection period was extended; namely, 261, 626, and 1103 circRNAs exhibited differential expression in cells infected for $6 \mathrm{~h}, 12 \mathrm{~h}$, and $20 \mathrm{~h}$, respectively. GO and KEGG enrichment analysis revealed significant enrichment of the parental genes of the differentially expressed circRNAs for viral replication and immune response-related pathways, such as positive regulation of transcription from the RNA polymerase II promoter, positive regulation of I-kappaB kinase/NF-kappaB signaling, innate immune response, and ubiquitin protein ligase activity. In conclusion, we identified the expression profile of circRNAs in H5N1-infected chicken DF1 cells. Bioinformatic analyses of the dysregulated circRNAs suggest that circRNAs might play important roles in the pathogenesis of H5N1 infection, offering new insights into the mechanisms underlying H5N1-host interaction.
\end{abstract}

Keywords: RNA-seq; H5N1; chicken; circRNA; DF1

\section{Introduction}

Influenza viruses belonging to the family Orthomyxoviridae are serious clinical and veterinary pathogens that cause epithelial cells to produce enveloped pleomorphic virions [1]. Influenza viruses can be classified into three types, A, B, and C, based on their major antigenic differences. Avian influenza virus (AIV) is of the A type, and is an important zoonotic pathogen [2] that can cause serious epidemics in poultry and result in substantial economic losses. Poultry infected with AIV exhibit reduced egg production, loss of appetite, soft or misshapen eggs, and even diarrhea and sudden death [3]. The first documented cases of human death caused by avian influenza virus infection were due to H5N1, a highly pathogenic avian influenza virus (HPAIV) first detected in Hong Kong in $1997[4,5]$. The H5N1 virus outbreak had devastating effects on the poultry industry, and 
the high pathogenicity of the virus provoked worldwide concern, but the pathogenesis underlying its infection is not yet fully clear.

Circular RNAs (circRNAs) comprise a novel category of RNAs with a "back-splicing" structure that confers remarkable tolerance to exonucleases [6,7]. CircRNAs are generated by the back-splicing of exonic, intronic, or intergenic regions. With the advance of highthroughput RNA sequencing (RNA-seq) technology, circRNAs were shown to be produced from thousands of loci in eukaryotes, from plants, animals to human beings [8,9], and were demonstrated to participate in multiple biological processes $[10,11]$. In recent years, they have been found to contribute substantially to host-virus interactions, specifically participating in the process of viral infection and the antiviral immune response. Transfection of circRNAs into mammalian cells can induce an innate immune response and confer protection against viral infection [12]. Lu et al. found that in cells infected with the Hantaan virus (HTNV), circ_0000479 regulated RIG-I expression by sponging miR-149-5p, thereby inhibiting viral replication [13]. Similarly, an artificial, designed circRNA was demonstrated to inhibit viral protein production in the $\mathrm{HCV}$ cell culture system by effectively sequestering cellular miR-122 [14], and abnormally expressed circRNAs in patients with chronic HBV infection may participate in immune regulation by regulating related miRNAs and their target genes [15]. However, while accumulated evidence has demonstrated substantial roles of circRNAs in viral pathogenesis, their particular roles in the pathogenesis of H5N1 remain largely unknown.

In this study, we used RNA-seq to investigate the expression profile of circRNAs and their potential roles in H5N1-infected chicken DF1 cells. Identifying the roles of dysregulated circRNAs could reveal their contributions to the interaction between H5N1 and the host. Our results provide novel insights into the mechanisms underlying $\mathrm{H} 5 \mathrm{~N} 1$ pathogenesis.

\section{Materials and Methods}

\subsection{Cell Culture and Viral Infection}

Chicken embryo fibroblast (DF1) cells obtained from the cell bank of the Chinese Academy of Agricultural Sciences were cultured in DMEM (Gibco) supplemented with $10 \%$ fetal bovine serum and $1 \%$ double antibody at $37{ }^{\circ} \mathrm{C}$ and $5 \% \mathrm{CO}_{2}$. The highly pathogenic H5N1 strain A/wild duck/Huadong/S/2005 (SY) was propagated in tenday-old non-specific pathogenic embryonic eggs. Viral titers were determined using the Reed and Muench method [16]. DF1 cells were infected at 0.01 multiplicity of infection (MOI) with H5N1 avian influenza virus for 6, 12, or $20 \mathrm{~h}$, and uninfected DF1 cells were used as the control group. Three biological replicates were performed for each group. All live virus experiments were carried out in biosafety cabinets with HEPA filters in the Biosafety Level III Laboratory of Yangzhou University.

\subsection{RNA Sequencing}

Total RNA was isolated using TRIzol reagent (Life Technologies, Grand Island, NY, USA), and rRNA was subsequently removed from the total RNA using a Ribo-Zero Magnetic Kit (Epidemiology) (Epicentre). Next, RNA from each biological replicate was randomly broken into small fragments of about $200 \mathrm{bp}$, and cDNA libraries were constructed according to the instructions of the Illumina kit (Illumina, San Diego, CA, USA). Subsequently, paired-end sequencing with 150-bp read length was performed using the Illumina HiSeq 4000 platform. The sequencing data were submitted to the Genome Sequence Archive (GSA, https://ngdc.cncb.ac.cn/gsa/, accessed on 28 December 2021) with the accession number CRA005692.

\subsection{Sequencing Data Analysis}

To improve the reliability of circRNA identification, two programs, find_circ (v1.2) [17] and CIRCexplorer2 [18], were used to identify circRNAs, with their suggested settings. After removing low-quality reads, clean reads were mapped to the chicken reference genome (http:/ / www.ensembl.org/Gallus_gallus/Info/Index, accessed on 28 December 
2021) using the designated reads aligner recommended by the corresponding circRNA identification program. Subsequently, the sequencing data that could not be mapped to the reference genome directly were subjected to detection of back-splice junctions for circRNA annotation using the find_circ (v1.2) and CIRCexplorer2 programs with their default parameters. CircRNAs predicted by both programs were considered as candidate circRNAs for further analysis. The limma package (v3.32.10) [19] was used to identify the differentially expressed circRNAs (DE circRNAs). CIRCexplorer2 software was also used to annotate the parental genes of the circRNAs [18].

\subsection{GO and KEGG Pathway Analysis}

To analyze the functions of the differentially expressed circRNAs (DE circRNAs), we performed Gene Ontology (GO) and Kyoto Encyclopedia of Genes and Genomes (KEGG) pathway enrichment analyses on the parental genes of the DE circRNAs using the Database for Annotation Visualization and Integrated Discovery (DAVID, version 6.8; https: / / david.ncifcrf.gov /, accessed on 28 December 2021) [20] and the KEGG database (http:/ / www.genome.jp/kegg/, accessed on 28 December 2021) [21].

\section{Results}

\subsection{Characteristics of circRNAs}

To identify the circRNA expression profile of DF1 cells infected with the highly pathogenic H5N1 avian influenza virus, we performed circRNA sequencing using rRNAdepleted total RNA from uninfected DF1 cells, as well as DF1 cells infected for $6 \mathrm{~h}, 12 \mathrm{~h}$, and $20 \mathrm{~h}$. A total of 14,586 circRNAs were identified. Exonic-derived circRNAs were the major type, accounting for about $69 \%$ of all detected circRNAs, while intergenic- and intronic-derived circRNAs only accounted for $13 \%$ and $11 \%$, respectively (Figure 1a). We found circRNAs to be widely distributed across chromosomes, with the greatest number of circRNAs being located on chromosome 1 (Figure 1b). The distribution pattern of circRNAs across chromosomes is perfectly consistent with the chromosome length of chickens.

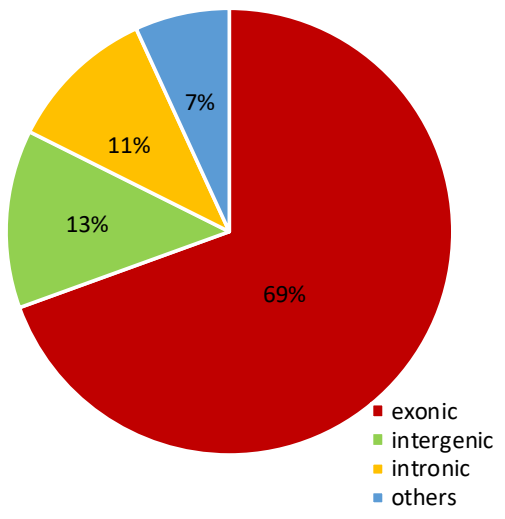

(a)

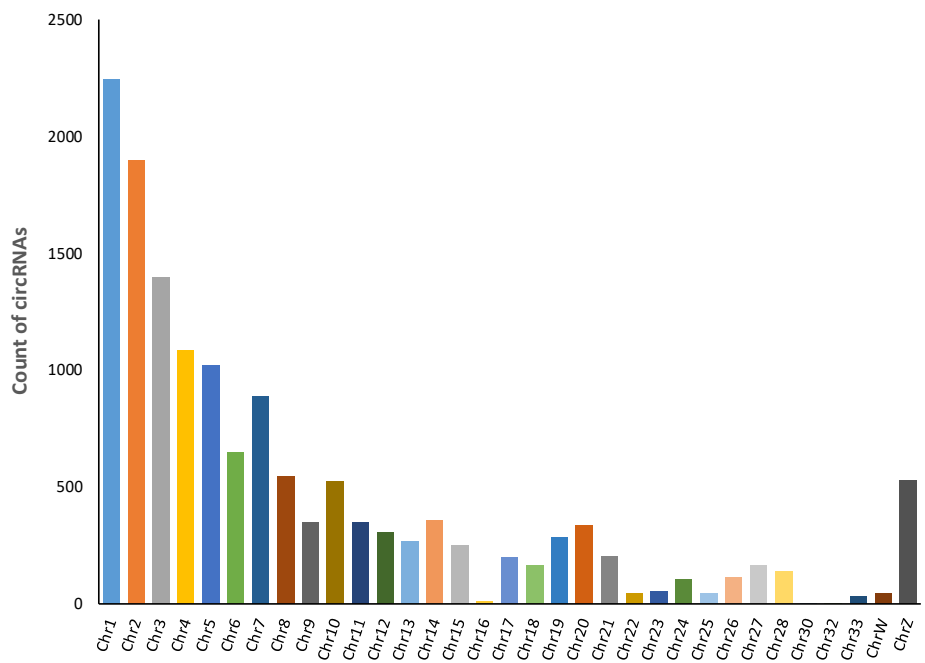

(b)

Figure 1. Characteristics of circRNAs. (a) Breakdown by circRNA type; (b) chromosome distribution of all identified circRNAs.

\subsection{Identification of Differentially Expressed circRNAs}

CircRNAs with fold changes $\geq 2.0$ relative to the uninfected group and $p$-values $\leq 0.05$ were considered to be significantly differentially expressed. Under this definition, 261, 626, and 1103 circRNAs, respectively, exhibited differential expression after $6 \mathrm{~h}, 12 \mathrm{~h}$, and $20 \mathrm{~h}$ of infection (Figure 2a). Of the differentially expressed circRNAs (DE circRNAs), 36 showed 
differential expression across all comparison pairs (Figure 2b). These circRNAs were annotated to 21 parental genes, of which seven had functions relating to immune response or virus infection, such as CD2AP, QKI, and AKIRIN2 (Table 1). Hierarchical cluster analysis of all of the DE circRNAs revealed that circRNAs exhibited different expression patterns after different infection durations. That is, circRNA expression profiles could be used to classify samples into branches consistent with infection duration (Figure 2c). Overall, circRNA expression increased with infection time and was highest at $20 \mathrm{~h}$ of infection.

Table 1. Parental genes of the 36 common differentially expressed circRNAs. Genes relating to viral infection or immune response were annotated and highlighted in boldface.

\begin{tabular}{|c|c|c|c|c|}
\hline CircRNA & Regulation & Gene Symbol & Terms/Pathways & Annotated Database \\
\hline CIRI_circ_006230 & down & - & & \\
\hline CIRI_circ_0013435 & $\begin{array}{l}\text { down }(6: 0) \\
\text { up }(12: 0 ; 20: 0)\end{array}$ & ALKBH8 & & \\
\hline CIRI_circ_0011785 & down & - & & \\
\hline CIRI_circ_007242 & down & RPL14 & Influenza virus RNA transcription and replication. & Gene cards \\
\hline CIRI_circ_002201 & down & - & & \\
\hline CIRI_circ_008390 & down & - & & \\
\hline CIRI_circ_006022 & down & - & & \\
\hline CIRI_circ_008353 & down & cuX1 & $\begin{array}{l}\text { Component of nf-munr repressor; binds to the matrix } \\
\text { attachment regions (MARs) of the immunoglobulin heavy } \\
\text { chain enhancer. Represses T-cell receptor beta enhancer } \\
\text { function by binding to MARbeta. }\end{array}$ & UniProtKB/Swiss-Prot \\
\hline CIRI_circ_008531 & up & COL3A1 & & \\
\hline CIRI_circ_0011293 & down & CANX & $\begin{array}{l}\text { Influenza virus RNA transcription and replication, and the } \\
\text { innate immune system. }\end{array}$ & UniProtKB/Swiss-Prot \\
\hline CIRI_circ_003013 & down & COL3A1 & & \\
\hline CIRI_circ_008959 & down & - & & \\
\hline CIRI_circ_002330 & up & AZIN1 & & \\
\hline CIRI_circ_0095 & $\begin{array}{l}\text { down }(6: 0) \\
\text { up }(12: 0 ; 20: 0)\end{array}$ & - & & \\
\hline CIRI_circ_005370 & down & - & & \\
\hline CIRI_circ_007453 & up & - & & \\
\hline CIRI_circ_00136 & $\begin{array}{l}\text { down }(6: 0 ; 12: 0) \\
\text { up }(20: 0)\end{array}$ & - & & \\
\hline CIRI_circ_004926 & up & TTC28 & & \\
\hline CIRI_circ_005366 & up & AKIRIN2 & Required for the innate immune response. & UniProtKB/Swiss-Prot \\
\hline CIRI_circ_0013703 & up & $M A F G$ & & \\
\hline CIRI_circ_003547 & up & RPS6KA5 & Activates TLR4 signaling and CNTF signaling. & UniProtKB/Swiss-Prot \\
\hline CIRI_circ_003861 & down & VNN2 & & \\
\hline CIRI_circ_00491 & $\begin{array}{l}\text { down }(6: 0) \\
\text { up }(12: 0 ; 20: 0)\end{array}$ & DROSHA & & \\
\hline CIRI_circ_0013304 & down & IGF1R & & \\
\hline CIRI_circ_0014096 & down & - & & \\
\hline CIRI_circ_004792 & down & TCP1 & & \\
\hline CIRI_circ_0010535 & down & - & & \\
\hline CIRI_circ_003044 & up & ATRNL1 & & \\
\hline CIRI_circ_008077 & up & - & & \\
\hline CIRI_circ_0012305 & up & $C D 2 A P$ & $\begin{array}{c}\text { May play a role in receptor clustering and cytoskeletal } \\
\text { polarity in the junction between T-cell and } \\
\text { antigen-presenting cell. }\end{array}$ & UniProtKB/Swiss-Prot \\
\hline CIRI_circ_008738 & down & LARGE1 & & \\
\hline CIRI_circ_002188 & up & DNAJB6 & & \\
\hline CIRI_circ_007562 & up & $Q K I$ & HIV Life Cycle and Oncogenic MAPK signaling & GeneCards \\
\hline CIRI_circ_002400 & up & TMEM214 & & \\
\hline CIRI_circ_009497 & up & MPP6 & & \\
\hline CIRI_circ_0014262 & down & - & & \\
\hline
\end{tabular}



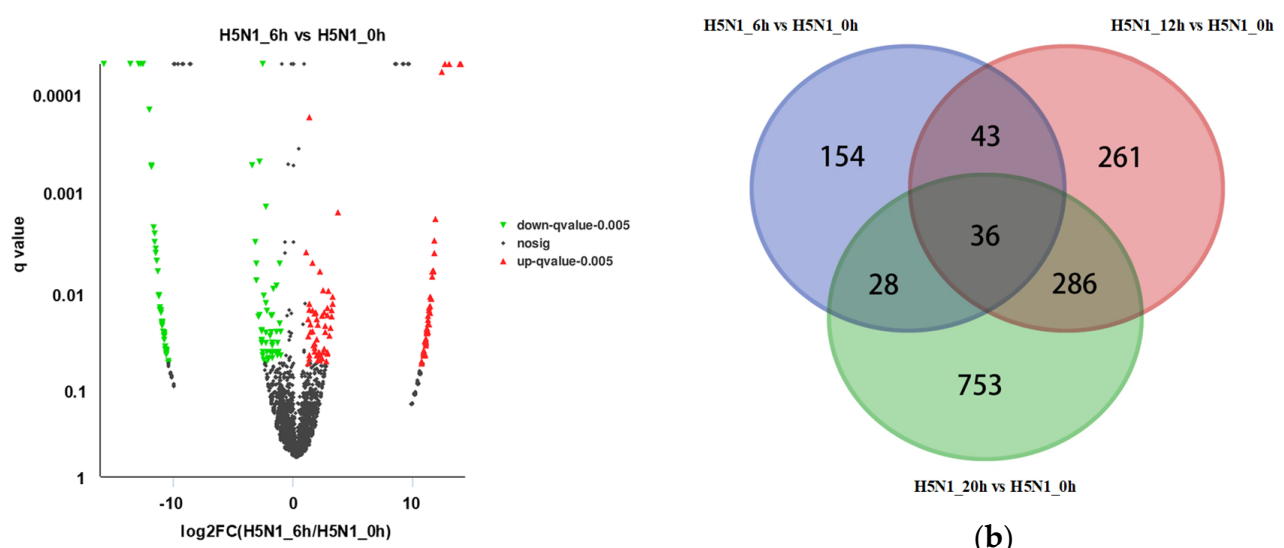

(b)
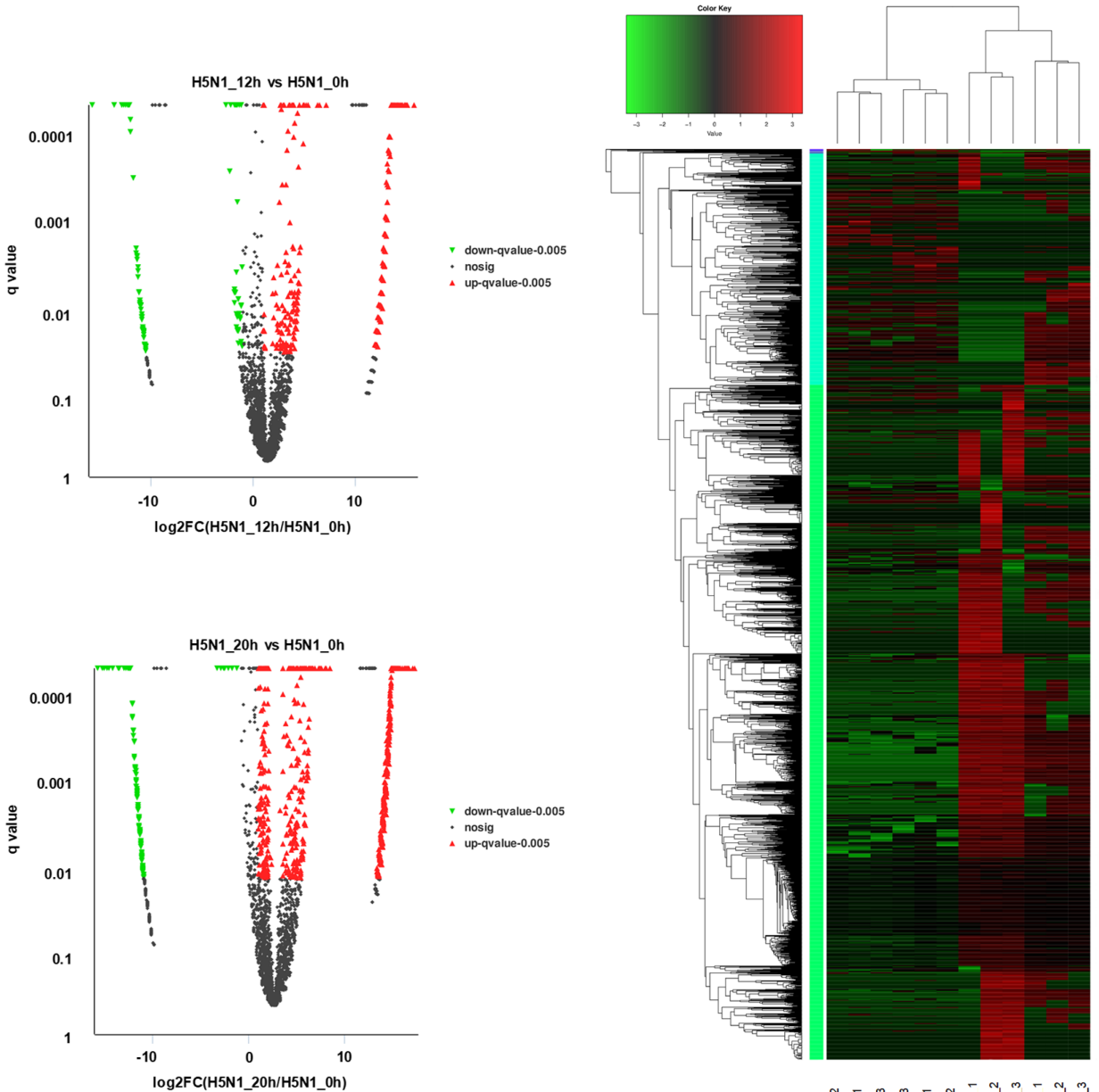

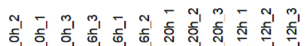

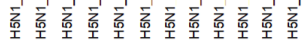

(a)

(c)

Figure 2. CircRNA expression changes in chicken DF1 cells infected with H5N1 avian influenza virus. (a) Volcano plot of circRNA expression. X-axis represents log2 (fold change) of circRNA expression; Y-axis represents q-value of circRNA expression changes. Red dots represent significantly upregulated circRNAs and green dots represent significantly downregulated circRNAs; (b) Venn diagram showing overlap of the differentially expressed circRNAs among timepoints; (c) hierarchical clustering heatmap of the DE circRNAs. Red represents high expression and green represents low expression. H5N1_0h, H5N1_6h, H5N1_12h, and H5N1_20h represent the uninfected group, 6-h infected group, 12-h infected group, and 20-h infected group, respectively. 


\subsection{Functional Analysis of the Parental Genes of DE circRNAs}

To identify the biological functions of the DE circRNAs in H5N1 infection, both GO and KEGG enrichment analyses were performed for the parental genes of the DE circRNAs. GO annotation analysis revealed significant enrichment of the viral replicationrelated categories, including "positive regulation of transcription from RNA polymerase II promoter" and "regulation of transcription from RNA polymerase II promoter" in the parental genes of the DE circRNAs for all H5N1 infected groups (Table S1). It is very interesting that immune response-related categories started to appear in the 12-h infected groups and increased in the 20-h infected groups. As shown in Table S1, the parental genes in the 12-h infected cells were enriched for immune response-related categories, including "positive regulation of I-kappaB kinase/NF-kappaB signaling" and "ubiquitinprotein transferase activity", but the 20-h infected groups exhibited more immune responserelated categories, such as "positive regulation of I-kappaB kinase/NF-kappaB signaling", "negative regulation of NF-kappaB import into nucleus", "innate immune response", and "ubiquitin protein ligase activity". KEGG pathway enrichment analysis, likewise, showed that a large number of parental genes of the 20-h DE circRNAs were principally enriched in immune response-related pathways, such as the "MAPK signaling pathway", "Endocytosis", "Ubiquitin mediated proteolysis", and "Herpes simplex infection" (Table 2).

Table 2. KEGG pathway enrichments of the parental genes of the circRNAs differentially expressed during H5N1 infection.

\begin{tabular}{|c|c|c|c|}
\hline Group & Enriched Pathways & $\begin{array}{l}\text { Enriched } \\
\text { Genes }\end{array}$ & $p$-Value \\
\hline \multirow{4}{*}{$\begin{array}{c}\text { 6-h infected } \\
\text { group }\end{array}$} & Dorsoventral axis formation & 3 & $3.40 \times 10^{-2}$ \\
\hline & Focal adhesion & 7 & $3.50 \times 10^{-2}$ \\
\hline & Wnt signaling pathway & 5 & $7.40 \times 10^{-2}$ \\
\hline & FoxO signaling pathway & 5 & $7.60 \times 10^{-2}$ \\
\hline \multirow{7}{*}{$\begin{array}{l}\text { 12-h infected } \\
\text { group }\end{array}$} & Focal adhesion & 11 & $1.20 \times 10^{-2}$ \\
\hline & Adherens junction & 6 & $2.20 \times 10^{-2}$ \\
\hline & SNARE interactions in vesicular transport & 4 & $3.10 \times 10^{-2}$ \\
\hline & Tight junction & 6 & $3.40 \times 10^{-2}$ \\
\hline & Cell cycle & 7 & $4.60 \times 10^{-2}$ \\
\hline & Ribosome biogenesis in eukaryotes & 5 & $7.10 \times 10^{-2}$ \\
\hline & ECM-receptor interaction & 5 & $9.50 \times 10^{-2}$ \\
\hline \multirow{13}{*}{$\begin{array}{l}\text { 20-h infected } \\
\text { group }\end{array}$} & MAPK signaling pathway & 20 & $8.60 \times 10^{-4}$ \\
\hline & Oocyte meiosis & 12 & $8.90 \times 10^{-4}$ \\
\hline & Endocytosis & 17 & $1.60 \times 10^{-2}$ \\
\hline & Focal adhesion & 15 & $1.80 \times 10^{-2}$ \\
\hline & Adherens junction & 8 & $2.00 \times 10^{-2}$ \\
\hline & Ubiquitin mediated proteolysis & 11 & $2.80 \times 10^{-2}$ \\
\hline & Regulation of actin cytoskeleton & 14 & $2.80 \times 10^{-2}$ \\
\hline & Progesterone-mediated oocyte maturation & 8 & $3.30 \times 10^{-2}$ \\
\hline & Hedgehog signaling pathway & 4 & $5.20 \times 10^{-2}$ \\
\hline & FoxO signaling pathway & 10 & $5.60 \times 10^{-2}$ \\
\hline & mRNA surveillance pathway & 7 & $6.20 \times 10^{-2}$ \\
\hline & Herpes simplex infection & 11 & $6.20 \times 10^{-2}$ \\
\hline & Adrenergic signaling in cardiomyocytes & 9 & $8.70 \times 10^{-2}$ \\
\hline
\end{tabular}

\section{Discussion}

Infection of chicken cells by the avian influenza virus results in dysregulation of the host transcription program. Large numbers of genes have been shown to be differentially expressed upon influenza virus infection [22-24]. Furthermore, infection activates many immune related-pathways, including the RIG-I pathway and the TLR, MAPK, TGF-beta, and NF- $\mathrm{KB}$ signaling pathways [22]. Beyond the alteration of messenger RNA transcription 
in influenza virus-infected cells, recent evidence has shown that circRNAs play crucial roles in the host response to influenza virus infection. In the current investigation, we identified 14,586 circRNAs. Consistent with current studies [25,26], exonic-derived circRNAs comprise the majority of identified circRNAs, compared with types of circRNAs arising from intronic and intergenic regions. Of the identified circRNAs, hundreds of differentially expressed circRNAs were identified in chicken DF1 cells infected with the H5N1 avian influenza virus, suggesting that circRNA expression is affected by the influenza virus and may participate in the pathogenesis of $\mathrm{H} 5 \mathrm{~N} 1$ infection. However, it is worth noting that these circRNAs need to be experimentally validated to exclude false positives.

circRNAs are posited to function in pathological conditions, such as virus infection, due to their potential to form competitive endogenous RNA (ceRNAs) that regulate innate immune responses [11]. There is also evidence that viral genomes could encode circRNAs that might function in viral infection $[27,28]$. Regarding particular known involvements of circRNAs, a study by Li and colleagues showed that activation of the innate immune sensor PKR induced nuclear export of NF90/NF110, which has promotive roles in circRNA biogenesis to inhibit viral infection [29]. In mice, infection with the H7N9 influenza virus induced differential expression of hundreds of circRNAs that play immune regulatory roles [30]. There is also evidence that host circRNAs were utilized to facilitate virus replication. For example, the human circRNA_0050463 facilitates IAV replication through sponging miR-33b-5p to regulate EEF1A1 [31]. The differentially expressed circRNAs in chicken DF1 cells infected with the H5N1 avian influenza virus were significantly involved in viral replication-related pathways, such as positive regulation of transcription from the RNA polymerase II promoter, and immune response-related pathways, such as positive regulation of I-kappaB kinase/NF-kappaB signaling, innate immune response, and ubiquitin protein ligase activity, suggesting that the H5N1 virus might escape or change the host's immune response through affecting circRNA expression. These findings suggest that circRNAs might participate in the pathogenesis of H5N1 infection. Our study provides basic information regarding the transcription dynamics of circRNAs upon avian influenza virus infection; it would be helpful for a future study to conduct functional validation of the roles of circRNAs in AIV infection.

\section{Conclusions}

H5N1 is a highly pathogenic avian influenza virus that seriously harms the poultry industry and public health worldwide. In this study, we identified the expression profile of circRNAs in H5N1-infected chicken DF1 cells and found hundreds of circRNAs to be differentially expressed. The differentially expressed circRNAs were significantly enriched in terms relating to virus replication and immune response, suggesting that circRNAs might play important roles in the pathogenesis of H5N1 infection. Our study provides new insights into the mechanisms underlying the H5N1-host interaction.

Supplementary Materials: The following are available online at https: / www.mdpi.com/article/ 10.3390/ani12020158/s1, Table S1: GO analysis of the parental genes of circRNAs differentially expressed during H5N1 infection.

Author Contributions: Conceptualization, L.C. and L.L.; methodology, L.C. and G.L.; validation, L.C. and W.X.; investigation, T.Z. and G.L.; resources, T.G.; data curation, L.C., T.Z., Y.T. and W.X.; writing-original draft preparation, L.C.; writing-review and editing, L.L.; visualization, L.L.; supervision, L.L.; project administration, L.L.; funding acquisition, L.L. All authors have read and agreed to the published version of the manuscript.

Funding: This research was supported by China Agriculture Research System of MOF and MARA (CARS-42-6).

Institutional Review Board Statement: Not applicable.

Informed Consent Statement: Not applicable.

Data Availability Statement: Not applicable. 
Conflicts of Interest: The authors declare no conflict of interest.

\section{References}

1. Noda, T.; Sagara, H.; Yen, A.; Takada, A.; Kida, H.; Cheng, R.H.; Kawaoka, Y. Architecture of ribonucleoprotein complexes in influenza A virus particles. Nature 2006, 439, 490-492. [CrossRef]

2. MacMahon, K.L.; Delaney, L.J.; Kullman, G.; Gibbins, J.D.; Decker, J.; Kiefer, M.J. Protecting poultry workers from exposure to avian influenza viruses. Public Health Rep. 2008, 123, 316-322. [CrossRef] [PubMed]

3. Xu, X.; Subbarao, K.; Cox, N.J.; Guo, Y. Genetic characterization of the pathogenic influenza A/Goose/Guangdong/1/96 (H5N1) virus: Similarity of its hemagglutinin gene to those of H5N1 viruses from the 1997 outbreaks in Hong Kong. Virology 1999, 261, 15-19. [CrossRef]

4. $\quad$ Claas, E.C.; Osterhaus, A.D.; van Beek, R.; De Jong, J.C.; Rimmelzwaan, G.F.; Senne, D.A.; Krauss, S.; Shortridge, K.F.; Webster, R.G. Human influenza A H5N1 virus related to a highly pathogenic avian influenza virus. Lancet (Lond. Engl.) 1998, 351, 472-477. [CrossRef]

5. Subbarao, K.; Klimov, A.; Katz, J.; Regnery, H.; Lim, W.; Hall, H.; Perdue, M.; Swayne, D.; Bender, C.; Huang, J.; et al Characterization of an avian influenza A (H5N1) virus isolated from a child with a fatal respiratory illness. Science 1998, 279, 393-396. [CrossRef]

6. Qu, S.; Yang, X.; Li, X.; Wang, J.; Gao, Y.; Shang, R.; Sun, W.; Dou, K.; Li, H. Circular RNA: A new star of noncoding RNAs. Cancer Lett. 2015, 365, 141-148. [CrossRef] [PubMed]

7. Memczak, S.; Jens, M.; Elefsinioti, A.; Torti, F.; Krueger, J.; Rybak, A.; Maier, L.; Mackowiak, S.D.; Gregersen, L.H.; Munschauer, M.; et al. Circular RNAs are a large class of animal RNAs with regulatory potency. Nature 2013, 495, 333-338. [CrossRef] [PubMed]

8. Zhang, X.O.; Wang, H.B.; Zhang, Y.; Lu, X.; Chen, L.L.; Yang, L. Complementary sequence-mediated exon circularization. Cell 2014, 159, 134-147. [CrossRef]

9. Ivanov, A.; Memczak, S.; Wyler, E.; Torti, F.; Porath, H.T.; Orejuela, M.R.; Piechotta, M.; Levanon, E.Y.; Landthaler, M.; Dieterich, C.; et al. Analysis of intron sequences reveals hallmarks of circular RNA biogenesis in animals. Cell Rep. 2015, 10, 170-177. [CrossRef]

10. Zheng, S.; Zhang, X.; Odame, E.; Xu, X.; Chen, Y.; Ye, J.; Zhou, H.; Dai, D.; Kyei, B.; Zhan, S.; et al. CircRNA-Protein Interactions in Muscle Development and Diseases. Int. J. Mol. Sci. 2021, 22, 3262. [CrossRef]

11. Tang, Q.; Hann, S.S. Biological Roles and Mechanisms of Circular RNA in Human Cancers. Onco Targets Ther. 2020, 13, $2067-2092$. [CrossRef] [PubMed]

12. Chen, Y.G.; Kim, M.V.; Chen, X.; Batista, P.J.; Aoyama, S.; Wilusz, J.E.; Iwasaki, A.; Chang, H.Y. Sensing Self and Foreign Circular RNAs by Intron Identity. Mol. Cell 2017, 67, 228-238.e5. [CrossRef]

13. Lu, S.; Zhu, N.; Guo, W.; Wang, X.; Li, K.; Yan, J.; Jiang, C.; Han, S.; Xiang, H.; Wu, X.; et al. RNA-Seq Revealed a Circular RNA-microRNA-mRNA Regulatory Network in Hantaan Virus Infection. Front. Cell. Infect. Microbiol. 2020, 10, 97C. [CrossRef]

14. Jost, I.; Shalamova, L.A.; Gerresheim, G.K.; Niepmann, M.; Bindereif, A.; Rossbach, O. Functional sequestration of microRNA-122 from Hepatitis C Virus by circular RNA sponges. RNA Biol. 2018, 15, 1032-1039. [CrossRef]

15. Cao, L.; Xing, T.; Xu, H.; Ye, M.; Zhang, Q. Differential expression of circular RNA in patients with chronic HBV infection of different stages and related bioinformatic analysis. Chin. J. Clin. Infect. Dis. 2017, 10, 421-427.

16. Reed, L.J.; Muench, H. A simple method of estimating fifty per cent endpoint. Am. J. Epidemiol. 1938, 27, 493-497. [CrossRef]

17. Jeck, W.R.; Sorrentino, J.A.; Wang, K.; Slevin, M.K.; Burd, C.E.; Liu, J.; Marzluff, W.F.; Sharpless, N.E. Circular RNAs are abundant, conserved, and associated with ALU repeats. RNA 2013, 2, 141-157. [CrossRef] [PubMed]

18. Zhang, X.O.; Dong, R.; Zhang, Y.; Zhang, J.L.; Luo, Z.; Zhang, J.; Chen, L.L.; Yang, L. Diverse alternative back-splicing and alternative splicing landscape of circular RNAs. Genome Res. 2016, 26, 1277-1287. [CrossRef]

19. Ritchie, M.E.; Phipson, B.; Wu, D.; Hu, Y.; Law, C.W.; Shi, W.; Smyth, G.K. limma powers differential expression analyses for RNA-sequencing and microarray studies. Nucleic Acids Res. 2015, 43, e47. [CrossRef] [PubMed]

20. Huang da, W.; Sherman, B.T.; Lempicki, R.A. Bioinformatics enrichment tools: Paths toward the comprehensive functional analysis of large gene lists. Nucleic Acids Res. 2009, 37, 1-13. [CrossRef] [PubMed]

21. Kanehisa, M.; Goto, S.; Hattori, M.; Aoki-Kinoshita, K.F.; Itoh, M.; Kawashima, S.; Katayama, T.; Araki, M.; Hirakawa, M. From genomics to chemical genomics: New developments in KEGG. Nucleic Acids Res. 2006, 34, D354-D357. [CrossRef] [PubMed]

22. Ranaware, P.B.; Mishra, A.; Vijayakumar, P.; Gandhale, P.N.; Kumar, H.; Kulkarni, D.D.; Raut, A.A. Genome Wide Host Gene Expression Analysis in Chicken Lungs Infected with Avian Influenza Viruses. PLoS ONE 2016, 11, e0153671. [CrossRef] [PubMed]

23. Kumar, A.; Vijayakumar, P.; Gandhale, P.N.; Ranaware, P.B.; Kumar, H.; Kulkarni, D.D.; Raut, A.A.; Mishra, A. Genome-wide gene expression pattern underlying differential host response to high or low pathogenic H5N1 avian influenza virus in ducks. Acta Virol. 2017, 61, 66-76. [CrossRef]

24. Watanabe, C.; Uchida, Y.; Ito, H.; Ito, T.; Saito, T. Host immune-related gene responses against highly pathogenic avian influenza virus infection in vitro differ among chicken cell lines established from different organs. Vet. Immunol. Immunopathol. 2011, 144, 187-199. [CrossRef]

25. Gao, Y.; Wang, J.; Zhao, F. CIRI: An efficient and unbiased algorithm for de novo circular RNA identification. Genome Biol. 2015 16, 4. [CrossRef] 
26. Wang, C.; Tan, S.; Liu, W.R.; Lei, Q.; Qiao, W.; Wu, Y.; Liu, X.; Cheng, W.; Wei, Y.Q.; Peng, Y.; et al. RNA-Seq profiling of circular RNA in human lung adenocarcinoma and squamous cell carcinoma. Mol. Cancer 2019, 18, 134. [CrossRef]

27. Qiao, Y.; Zhao, X.; Liu, J.; Yang, W. Epstein-Barr virus circRNAome as host miRNA sponge regulates virus infection, cell cycle, and oncogenesis. Bioengineered 2019, 10, 593-603. [CrossRef]

28. Yu, T.; Ding, Y.; Zhang, Y.; Liu, Y.; Li, Y.; Lei, J.; Zhou, J.; Song, S.; Hu, B. Circular RNA GATAD2A promotes H1N1 replication through inhibiting autophagy. Vet. Microbiol. 2019, 231, 238-245. [CrossRef]

29. Li, X.; Liu, C.X.; Xue, W.; Zhang, Y.; Jiang, S.; Yin, Q.F.; Wei, J.; Yao, R.W.; Yang, L.; Chen, L.L. Coordinated circRNA Biogenesis and Function with NF90/NF110 in Viral Infection. Mol. Cell 2017, 67, 214-227.e7. [CrossRef] [PubMed]

30. Liu, Z.; Guo, Y.; Zhao, L.; Liu, Q.; Tian, M.; Huang, N.; Fan, M.; Yu, M.; Xia, H.; Ping, J. Analysis of the circRNAs expression profile in mouse lung with H7N9 influenza A virus infection. Genomics 2021, 113 Pt 2, 716-727. [CrossRef]

31. Shi, N.; Zhang, S.; Guo, Y.; Yu, X.; Zhao, W.; Zhang, M.; Guan, Z.; Duan, M. CircRNA_0050463 promotes influenza A virus replication by sponging miR-33b-5p to regulate EEF1A1. Vet. Microbiol. 2021, 254, 108995. [CrossRef] [PubMed] 